\title{
Biología reproductiva de tres especies de Polylepis (P. neglecta, $P$. incarum y $P$. pacensis), con énfasis en su comportamiento germinativo
}

\author{
Cecilia K. Vega ${ }^{1, \mathbb{D}}$; C. Gabriela Villegas ${ }^{1}$; Paola A. Rocabado'; Jorge A. N. \\ Quezada'; Mercy Y. López \& Ana W. Quevedo ${ }^{2}$
}

${ }^{1}$ Unidad de Biotecnología Vegetal del Instituto de Biología Molecular y Biotecnología. Carrera de Biología de la Universidad Mayor de San Andrés - U.M.S.A. ${ }^{2}$ Laboratorio de Botánica. Facultad de Ciencias Agrícolas. Universidad Autónoma Gabriel René Moreno - U.A.G.R.M.

\begin{abstract}
RESUMEN. Se desarrollaron diferentes estudios de germinación para contribuir al conocimiento de la reproducción sexual de especies nativas de Bolivia del género Polylepis ( $P$. neglecta, $P$. incarum y P. pacensis), como base para producir plantines destinados a la reforestación. Para obtener semillas, se identificaron potenciales árboles semilleros tanto en poblaciones naturales (P. pacensis y P. incarum) como en áreas verdes del Municipio de La Paz (P. neglecta). A su vez, se caracterizó la morfoanatomía de frutos y semillas por especie. Con relación a la calidad física, en función de la muestra (100 g de semillas por especie), se encontró un alto grado de impurezas, lo que dificultó obtener semilla pura para la siembra. El porcentaje de humedad de las semillas fue bajo: 10\% en $P$. incarum, $8 \%$ en $P$. pacensis y $6 \%$ en P. neglecta. Por esta razón, podrían considerarse semillas ortodoxas (i.e., se pueden almacenar por un período prolongado sin perder su poder germinativo). Se obtuvo una germinación de $10 \%$ (P. neglecta), $8 \%$ (P. pacensis) y $2 \%$ (P. incarum). Por otro lado, la respuesta germinativa de semillas de estas especies de Polylepis en condiciones de invernadero mostró el mayor porcentaje de germinación (19\%) en el sustrato arena+turba 1:1. La especie que mostró el mayor porcentaje de germinación fue $P$. neglecta (entre 10 y $15 \%$ ), mientras que $P$. pacensis y $P$. incarum presentaron 8 y $2 \%$, respectivamente. A pesar del bajo porcentaje germinativo que caracteriza al género Polylepis, contar con una buena cantidad de semillas y adecuadas condiciones para su desarrollo (i.e., humedad, sustrato, temperatura) hace posible su propagación masiva en condiciones de invernadero, con óptimos resultados en cuanto a cantidad y calidad de plantas.
\end{abstract}

[Palabras clave: conservación, germinación, morfoanatomía, reforestación]

Aвstract. Reproductive biology of three Polylepis species (P. neglecta, P. incarum and P. pacensis), with emphasis on their germinative behavior. With the purpose of contributing to the knowledge on the sexual reproduction of native species of Bolivia of the genus Polylepis (P. neglecta, P. incarum and P. pacensis), as a base for the production of seedlings destined for reforestation, different germination studies were developed. To obtain seeds, potential seed trees were identified both in natural populations ( $P$. pacensis and $P$. incarum) as well as in green areas of the Municipality of La Paz (P. neglecta). At the same time a fruit an seed morpho anatomical characterization by species was developed. In relation to the physical quality, depending on the sample, $100 \mathrm{~g}$ of seeds per species, a high degree of impurities was found, which made it difficult to obtain pure seed for sowing. The percentage of humidity of seeds was low: 10\% in $P$. incarum, $8 \%$ in $P$. pacensis and $6 \%$ in P. neglecta; as in consequence, they could be considered as orthodox seeds (i.e., can be stored for a long time without losing the germinative power). A germination of $10 \%(P$. neglecta), $8 \%$ (P. pacensis) and $2 \%(P$. incarum) was obtained. On the other hand, the germinative response of seeds of these Polylepis species under greenhouse conditions showed the highest percentage of germination $(19 \%)$ in the substrate sand+peat 1:1. The species with the highest percentage of germination was P. neglecta (10 to $15 \%)$, while P. pacensis and $P$. incarum showed 8 and $2 \%$, respectively. Despite the low germination percentage known for the genus Polylepis, having a good amount of seeds and adequate conditions for their development (i.e., humidity, substrate, temperature) makes possible to spread these species massively under greenhouse conditions, with optimal results in terms of quantity and quality of plants.

[Keywords: conservation, germination, morphoanatomy, reforestation]

Editora asociada: Erica Cuyckens

$\triangle$ kcecivegak@hotmail.com 


\section{INTRODUCCIÓN}

El género arborescente Polylepis (Rosaceae) está presente desde Venezuela hasta el Norte de Chile (Kessler 1995). Forma bosques que representan la vegetación natural de gran parte de los Andes centrales y aparece en diferentes hábitats, desde el límite superior de los bosques de neblina hasta los volcanes áridos del Altiplano (Kessler 2006). Los bosques de Polylepis, al igual que otros, ofrecen diferentes servicios ambientales: incrementan la precipitación y mantienen un clima local estable, detienen la escorrentía al interceptar agua y dejarla infiltrar dentro del suelo, contienen un sotobosque de plantas que protegen al suelo contra la erosión y retienen sedimentos y nutrientes, además de albergar una serie de especies de flora y fauna, en muchos casos endémicas (Kessler 2002; Fjeldså and Kessler 2004). Históricamente, los bosques de Polylepis han estado amenazados por la tala para leña y la producción de carbón vegetal, así como por el uso regular del fuego para estimular el rebrote de los pastos a fin de habilitar campos agrícolas. La amenaza más reciente es la reforestación con especies exóticas de eucaliptos y pinos (Fjeldså and Kessler 2004). Como resultado de siglos de intervención humana, se ha alterado su estructura, extensión y composición específica (Kessler and Driesch 1993). A esto se deben agregar las bajas tasas de germinación (2 al $50 \%$ ) reportadas para distintas especies de Polylepis, lo cual puede relacionarse con los porcentajes elevados de semillas vacías o no viables por la acción antropogénica sobre el hábitat (Prettel et al. 1985; Hensen 1994; Renison and Cingolani 1998; Renison et al. 2004). En consecuencia, dentro del marco de la estrategia para la conservación de bosques de Polylepis (Quewiña) y biodiversidad asociada en Bolivia, se determinó que estas formaciones boscosas son prioritarias para la conservación (MMAyA 2012). Sin embargo, a pesar de ello, estos ecosistemas forestales han sido y siguen siendo rápidamente degradados por la actividad humana. Por esta razón, la generación de información sobre aspectos de la reproducción de las especies de Polylepis podría ayudar, en alguna medida, al problema de la fragmentación de estos bosques (Seltmann et al. 2007). Por lo mencionado, la elaboración y la implementación de proyectos integrales para restaurar y recuperar los bosques de Polylepis y su biodiversidad debería incluir el trasplante de plantas juveniles y la reforestación con especies nativas (MMAyA
2012). Existen pocas publicaciones respecto a las metodologías y experiencias referidas a la propagación y reforestación de las diferentes especies de keñuas, por lo que es necesario conocer aspectos de la biología reproductiva de las especies destinadas a la reforestación, así como aspectos vinculados a su establecimiento. En este sentido, el presente estudio pretende contribuir al conocimiento de la reproducción sexual de tres especies de Polylepis: P. neglecta, P. incarum y P. pacensis, con énfasis en su comportamiento germinativo y con la finalidad de producir plantines para la reforestación.

\section{Materiales y Métodos}

\section{Localización y selección de árboles semilleros de Polylepis}

Para verificar las zonas con presencia de fragmentos boscosos de Polylepis, se georreferenciaron los puntos de muestreo y se realizó la selección de potenciales árboles semilleros en función de ejemplares que presentaran visualmente la mayor densidad relativa de frutos en el dosel (presencia de ramas con estructuras fértiles distribuidas en las distintas exposiciones de la copa). Asimismo, se registraron, marcaron y midieron parámetros alométricos básicos como altura, diámetro de tronco $\mathrm{DAP}_{50}$ (medido a $50 \mathrm{~cm}$ de la base) y se realizó la verificación e identificación taxonómica por especialistas del Herbario Nacional de Bolivia (LPB) de la Universidad Mayor de San Andrés (U.M.S.A.). Se realizaron salidas a campo hacia áreas próximas al Municipio de La Paz, donde se localizaron sectores con bosques de $P$. pacensis, como la localidad de Cohoni, a $\sim 75 \mathrm{~km}$ de la ciudad de La Paz, entre las coordenadas $16^{\circ} 42^{\prime} 42.9^{\prime \prime} \mathrm{S}$ y $67^{\circ} 50^{\prime} 18.4^{\prime \prime} \mathrm{O}$ y a una altitud de $3539 \mathrm{~m} \mathrm{s.} \mathrm{n.} \mathrm{m.} \mathrm{En} \mathrm{ella} \mathrm{se} \mathrm{ubicaron} \mathrm{distintos}$ puntos con presencia de fragmentos de estos bosques. Estas poblaciones se encontraban asentadas en laderas y quebradas de pendiente pronunciada; en función de su accesibilidad, se seleccionaron y registraron 8 árboles en estado de fructificación (i.e., presencia de frutos inmaduros, maduros y remanentes), con una altura media de 3.7 $\mathrm{m}$ y un $\mathrm{DAP}_{50}$ promedio de $17.5 \mathrm{~cm}$. En el Municipio de Puerto Carabuco, situado en la tercera sección de la Provincia Camacho del Departamento de La Paz, a una altitud media de $3860 \mathrm{~m}$ s. n. m., entre las coordenadas $15^{\circ} 32^{\prime} 17^{\prime \prime} \mathrm{S}$ y $69^{\circ} 25^{\prime} 06^{\prime \prime} \mathrm{O}$, se ubicaron dos puntos principales con presencia de bosques 
de $P$. incarum (fragmentos), asentados en laderas con pendiente pronunciada, donde se marcaron 33 ejemplares, en los que se diferenciaron estructuras florales y frutos (maduros, inmaduros y viejos). La altura y DAP $_{50}$ promedio registrados fueron de $3.5 \mathrm{~m}$ y $27.8 \mathrm{~cm}$, respectivamente. En el caso de $P$. neglecta, se localizó un número de semilleros previamente identificados en el Jardín Botánico La Paz, del Campus Universitario de la Facultad de Ciencias Puras y Naturales de la U.M.S.A., con coordenadas $16^{\circ} 32^{\prime} 18^{\prime \prime}$ S y 68 $04^{\prime} 7.99^{\prime \prime}$ O, a 3411 m s. n. m. Allí se marcaron 6 árboles en estado de floración y fructificación. En función de las mediciones realizadas, se calculó una altura promedio de $3.9 \mathrm{~cm}$ y $26.5 \mathrm{~cm}$ de $\mathrm{DAP}_{50}$.

\section{Distribución y hábitat}

Polylepis pacensis M. Kessler and SchmidtLeb., especie endémica de Bolivia de acuerdo con Arrázola y Coronado (2012), habita en valles secos interandinos y bosques de yungas, en un rango altitudinal que oscila entre 3200 y 4200 m s. n. m. En su hábitat natural forma pequeños bosques fragmentados en las laderas de cerros y roquedales a los pies del nevado Illimani (Gómez et al. 2014). Esta especie se localiza en el Departamento de La Paz, en la Provincia Murillo (Comunidad de Cohoni). Los bosques de Polylepis incarum (Bitter) M. Kessler and Scmidt-Leb. se encuentran distribuidos en los alrededores del Lago Titicaca en Perú y Bolivia, en el Departamento de La Paz, Provincia Manco Kapac. Habitan en laderas de cerros y zonas rocosas (Arrázola et al. 2012). También existen árboles aislados en medio de los cultivos agrícolas, a los que les proporcionan sombra y protección contra el viento. La vegetación del Lago Titicaca es característica de la puna húmeda y abarca los pisos ecológicos altimontano y altoandino inferior, que se encuentran entre 3600 y 4100 m s. n. m. (Navarro et al. 2010; citado en Domic et al. 2017). La región se caracteriza por una larga historia de ocupación humana que modificó intensamente el paisaje. La vegetación, dominada por matorrales y pajonales en medio de barbechos abandonados o en diferentes etapas de descanso (Navarro 2002), se encuentra mayormente degradada. Polylepis neglecta M. Kessler., especie endémica de Bolivia, se encuentra distribuida en los faldeos, serranías y vertientes hacia el este de la Cordillera Oriental de los Andes (Arrázola and Coronado 2012). Su rango altitudinal se encuentra entre 2400 y 3700 m s. n. m. Su distribución se extiende en el Centro-Sur de Bolivia, en los Departamentos de Cochabamba, Suroeste de Santa Cruz, Noreste de Potosí, Este de Chuquisaca y Tarija, propiamente en la cuenca interandina del Río Grande, con los Ríos Caine y Mizque y, además, la cuenca interandina del Rio Piray (Arrázola and Coronado 2012).

\section{Selección de las especies}

Las especies fueron seleccionadas tomando en cuenta los siguientes parámetros.

Disponibilidad de árboles semilleros. En función a revisión bibliográfica, se consideraron aquellas especies de Polylepis localizadas en zonas cercanas al Departamento de La Paz-Bolivia, principalmente por la restricción en el ámbito geográfico establecido por el financiador para llevar a cabo la presente investigación. En ese sentido, se seleccionaron las especies $P$. neglecta, $P$. incarum y $P$. pacensis.

Estado de conservación. P. neglecta está catalogada como Vulnerable (VU) y $P$. pacensis se encuentra dentro de la categoría En Peligro (EN), de acuerdo con Arrázola y Coronado (2012). P. incarum califica dentro de la categoría EN (Arrázola et al. 2012).

Crecimiento de las especies. Otro criterio de selección fue la velocidad de crecimiento, aspecto clave para los procesos posteriores de producción de las especies de interés. Algunos reportes informan que las plántulas de $P$. neglecta presentan rápido crecimiento (hasta $50 \mathrm{~cm}$ por año), mientras que reconocen a $P$. incarum como un árbol de crecimiento rápido. Por ello, ambas especies son consideradas como potenciales para la reforestación (Fjledså and Kessler 2004).

\section{Colecta de semillas}

Se efectuó la colecta de semillas en estado de madurez, para lo cual se utilizaron criterios de coloración (frutos de color café claro) y grado de adherencia al racimo (fácilmente desprendibles), tal como sugiere Lojan (1992). Sin embargo, en el proceso se observaron semillas inmaduras (verdes) bastante adheridas al racimo y semillas viejas (café oscuras) muy sueltas al contacto con la mano. La recolección de semillas se hizo manualmente para desprender los frutos. Aun así, fue inevitable obtener muestras con diferente grado de madurez. La cantidad de 
semilla colectada por árbol de cada especie fue variable. En laboratorio fue homogeneizada (mezcla de muestras primarias) y reducida a $\sim 100$ g en las especies $P$. neglecta y $P$. incarum, y de sólo $30 \mathrm{~g}$ en el caso de P. pacensis. A partir de estas muestras se realizó la distribución de las semillas en función de la cantidad requerida para cada uno de los análisis realizados.

\section{Caracterización morfoanatómica de frutos y semillas}

Por un lado, para la caracterización morfológica se tomaron 10 aquenios completos, es decir, que presentaban semillas con todas sus estructuras. Por otro lado, para la caracterización anatómica se tomaron otros frutos con semillas, distintos a los que se usaron para la descripción morfológica, y se realizaron cortes de por lo menos 10 muestras por especie.

Caracterización morfológica. De cada especie en estudio se utilizaron los aquenios completos, que fueron examinados en un microscopio estereoscópico Olympus SZX7 con cámara digital DP21, para determinar su forma, color, superficie y tamaño.

Caracterización anatómica. Se realizó a través de cortes transversales y longitudinales de los frutos y semillas, coloreados con una tinción diferencial con azul de astra-safranina (Luque et al. 1996). Para la detección de compuestos celulares específicos se realizaron pruebas histoquímicas. Los almidones fueron identificados con Lugol (Roth 1974), mientras que las paredes cutinizadas y los lípidos en general se identificaron con Sudán III (Johansen 1940). Asimismo, se elaboraron láminas semipermanentes en criostato marca Slee Mev, para lo cual las muestras fueron colocadas en un soporte y embebidas con CryoGlue. Posteriormente, las muestras fueron llevadas al criostato por media hora, a una temperatura de $-10{ }^{\circ} \mathrm{C}$, para luego ser cortadas en el micrótomo con un grosor de $80 \mu \mathrm{m}$ y teñidas con la misma coloración diferencial. Todas las muestras histológicas fueron montadas entre un porta- y un cubreobjetos, fijadas y selladas con una gota de gelatina glicerinada (Stevens 1916). Las descripciones y fotografías anatómicas de los frutos y semillas se basaron en observaciones realizadas en un microscopio trinocular Olympus BX53 equipado con cámara digital DP21. Se empleó luz polarizada para la localización de los cristales.
Análisis de calidad de las semillas

En base a la metodología estandarizada por la Internacional Seed Testing Association (ISTA 2003), para cada especie en estudio se realizaron los ensayos de la calidad física y fisiológica de semillas en las instalaciones de la Unidad de Biotecnología Vegetal (U.B.V.) de la U.M.S.A. El detalle figura a continuación.

Calidad física. Comprendió los análisis para determinar la pureza física, el contenido de humedad y el peso de 1000 semillas. El análisis de pureza física se realizó inmediatamente después de que las semillas fueron colectadas. Este análisis consistió en examinar una muestra de $100 \mathrm{~g}$ de semillas por especie (con excepción de $P$. pacensis por no obtener el tamaño muestral) y separar a mano la semilla pura de las impurezas (semilla de otras especies y materia inerte) con la ayuda de lupas de disección marca Rowland, con un foco circular de 22 watts y un aumento de 5X, para luego pesarlas y calcular el porcentaje de pureza utilizando la siguiente fórmula (Danida and FAO 1991):

$\underset{\text { Porcentaje de }}{\text { pureza }}=\frac{\text { Peso de la semilla pura }}{\text { Peso total de la muestra original }} \times 100$

Posteriormente, se procedió a determinar el contenido de humedad de la semilla por el método recomendado por el ISTA (1993). Se pesaron ocho muestras de 100 semillas, que fueron secadas en estufa (marca Binder) a una temperatura de $103 \pm 2{ }^{\circ} \mathrm{C}$ por 17 horas y luego pesadas nuevamente. El porcentaje de humedad se calculó a partir de la siguiente fórmula:

Porcentaje $=$ Peso original - Peso secado en estufa
de humedad

Para la evaluación del peso de 1000 semillas, éstas se separaron manualmente, con 8 repeticiones al azar por especie y cada una de ellas fue pesada en una balanza analítica.

Calidad fisiológica. Se realizó en primera instancia un ensayo exploratorio utilizando la prueba de viabilidad con tetrazolio en función de patrones de coloración que permitieron la evaluación confiable de la viabilidad de las semillas de las especies en estudio. De acuerdo con el procedimiento establecido por el ISTA (1993) se realizó un pre-acondicionamiento de las semillas, colocándolas durante 24 horas en papel toalla humedecido. Esto provocó la activación del sistema enzimático, además de 
facilitar el corte de la semilla y el desarrollo de una coloración más nítida y uniforme. A continuación, se realizó un corte transversal de las semillas para exponer el embrión directamente a la acción del tetrazolio y facilitar su penetración. Se realizaron 5 repeticiones de 20 semillas por caja Petri, haciendo un total de 100 semillas por especie. El siguiente paso fue la tinción de las semillas a través de su inmersión en la solución de tetrazolio, a una concentración de $0.5 \%$ por un lapso de $24 \mathrm{~h}$ en oscuridad y a temperatura ambiente. Para proceder a la interpretación de la prueba se utilizó un estereoscopio marca Labomed con un aumento de 20X. De esta manera, las semillas fueron clasificadas, de acuerdo con las zonas coloreadas, en distintas categorías de tinción establecidas según las normas ISTA: categoría 1: tejido vivo (TV1, coloración de tejido rojo intenso. TV2, coloración de tejido rosado brillante o intensa. TV3, coloración de tejido rosado claro); categoría 2: tejido deteriorado (TD1, coloración de tejido rojo granate. TD2, coloración de tejido rosado lechoso); categoría 3: tejido muerto (TM1, coloración de tejido descolorido/blancuzco o hialino. TM2, tejido necrosado con coloración marrón). Dado que se encontraron semillas vacías (sin embrión), para describir esta condición se agregó la categoría 4 (SSTE, semilla sin tejidos embrionarios). El principal atributo considerado en la calidad fisiológica de las semillas se refiere a su capacidad germinativa. En este sentido, se llevó a cabo un ensayo de germinación bajo condiciones ambientales controladas de humedad, temperatura y luz en la sala de crecimiento de la U.B.V., que cuenta con estantes con luz artificial, programados con un fotoperíodo de $16 \mathrm{~h} \mathrm{luz} / 8$ oscuridad y una temperatura media de $25{ }^{\circ} \mathrm{C}$. Se sembraron 6 semillas por caja Petri, con un total de 240 semillas por cada especie. El número de repeticiones (caja Petri) por especie fue 40. Como sustrato se utilizó papel toalla, que proporcionó la porosidad adecuada para la retención de humedad. Este ensayo duró 30 días, tiempo que se esperó para que ocurriera la máxima germinación. Durante este periodo se realizó, día por medio, el conteo de 1) semillas germinadas (aquellas que desarrollaron una plántula con estructuras esenciales, como raíces, tallo y cotiledones) y 2) semillas no germinadas.

\section{Germinación de semillas en invernadero}

Considerando la información disponible en trabajos previos sobre semillas de Polylepis, se llevaron a cabo dos ensayos en el invernadero del Jardín Botánico La Paz - U.M.S.A. En un primer ensayo (preliminar) se probaron cuatro tipos de sustratos: S1, arena+turba (1: 1) (sustrato control); $S 2$, arena+turba+tierra negra (1:1:1); S3, arena+turba+humus (2:1: 1); y $S 4$, arena+tierra negra (1:1). Previamente a la siembra, a las semillas se les realizó un tratamiento pre-germinativo de remojo en agua durante 24 horas. Se sembraron 240 semillas por especie; la mitad fue sometida a este procedimiento. El ensayo se realizó en julio, agosto y septiembre de 2015. Los datos obtenidos fueron analizados estadísticamente a través de un diseño completamente al azar con arreglo trifactorial; los factores fueron: especies (A), remojo (B) y sustratos (C), con 10 repeticiones por tratamiento. Luego se efectuó un segundo ensayo (final), en el cual se utilizaron los dos mejores sustratos provenientes del ensayo preliminar (S1 [arena+turba 1:1] y S4 [arena+tierra negra 1: 1]) para verificar la respuesta observada en el anterior ensayo y establecer tratamientos para posteriores procesos de producción. En ambos casos se aplicó el tratamiento pre-germinativo (remojo de semillas). Se sembraron 240 semillas por especie, de las cuales 120 fueron remojadas en agua para estandarizar una técnica para la propagación de plantines de keñua. Este ensayo se realizó en los meses de septiembre y octubre de 2015. Los resultados se analizaron a través de un diseño completamente al azar con arreglo bifactorial; los factores fueron especies (A) y tratamientos de sustratos con y sin remojo (B), con 40 repeticiones por tratamiento.

\section{Resultados}

\section{Caracterización morfoanatómica de frutos y semillas}

Morfología. Los frutos son aquenios indehiscentes, monospérmicos, de color castaño claro, con proyecciones laterales achatadas. Los frutos de $P$. neglecta son obovados, glabros, de $6.9 \pm 0.9 \mathrm{~mm}$ de longitud por $5.2 \pm 1.0 \mathrm{~mm}$ de ancho. En sección transversal son triangulares, con una cara plana y tres proyecciones laterales achatadas en forma de alas delgadas; las dos laterales opuestas son más largas que la central, formando costillas evidentes (Figuras 1 A y 1E). Por su parte, los frutos de P. incarum y $P$. pacensis tienen contorno romboidal, más anchos en la región próxima al ápice (forma obtrulada), de $7 \pm 1.2 \mathrm{~mm}$ de longitud por 

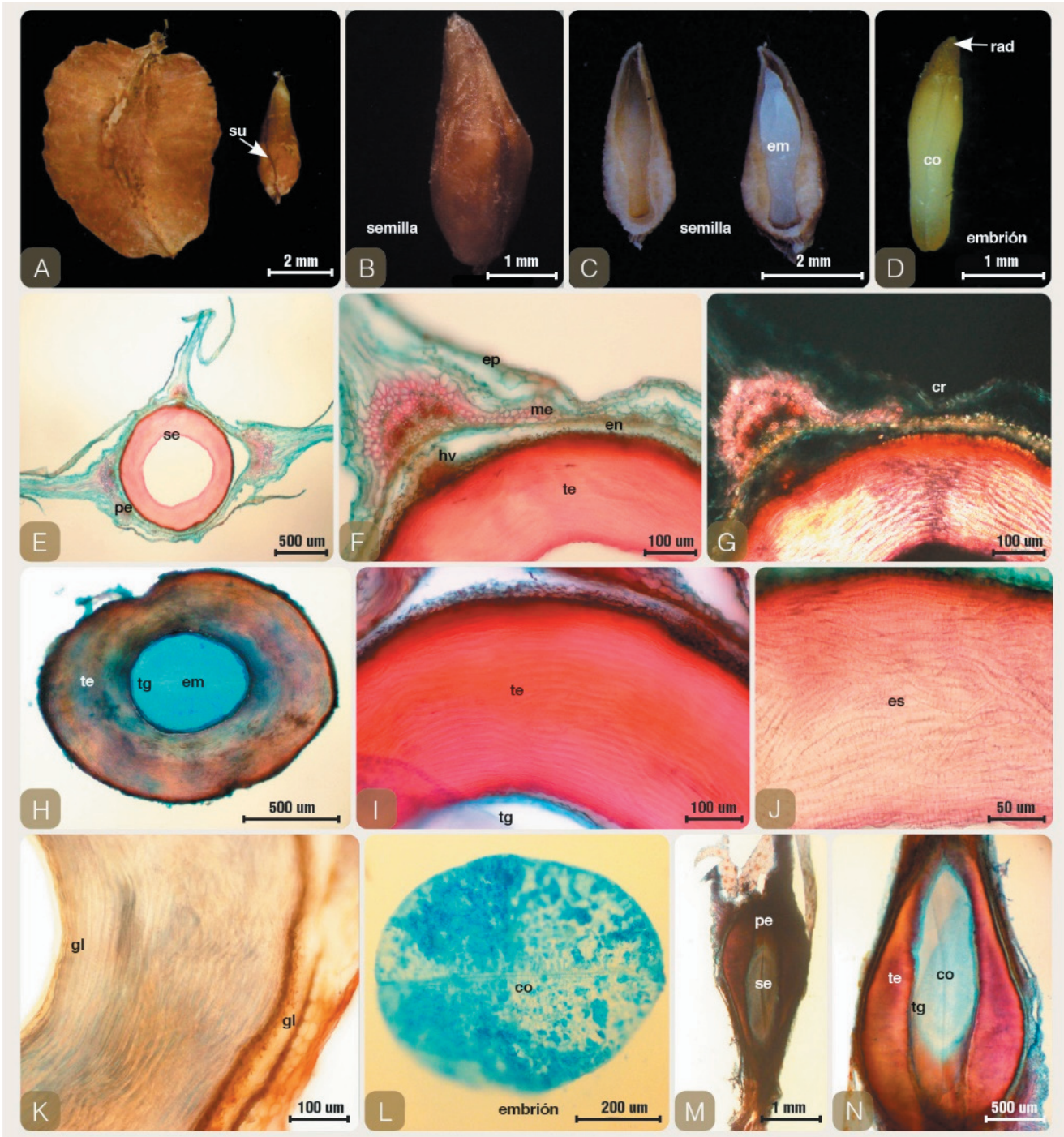

Figura 1. P. neglecta. Morfología A-D. (A) Aspecto general de la morfología del fruto y semilla. (B) Detalle de la semilla. (C) Corte longitudinal mostrando la posición del embrión. (D) Aspecto del embrión. Anatomía E-N. (E) Vista general del corte transversal del fruto y semilla. (F) Detalle del pericarpo y testa de la semilla. (G) Detalle de cristales en el mesocarpo y endocarpo, bajo luz polarizada. (H) Vista general del corte transversal de la semilla. (I) Detalle de la testa y tegmen. (J). Detalle de las esclereidas entrecruzadas. (K) Detalle del fruto y semilla, mostrando células que contienen gotas lipídicas. (L) Detalle del corte transversal del embrión. (M) Vista general del corte longitudinal del fruto y semilla. (N) Detalle del corte longitudinal del fruto y semilla. $c o=$ cotiledones, $\mathrm{cr}=\mathrm{cristales}$, em=embrión, en=endocarpo, ep=epicarpo, es=esclereidas, $\mathrm{gl}=$ gotas lipídicas, $\mathrm{hv}=$ haces vasculares, $\mathrm{me}=$ mesocarpo, $\mathrm{pe}=$ pericarpo, $\mathrm{rad}=$ radícula, se=semilla, $\mathrm{su}=$ sutura, te=testa, tg=tegmen .

Figure 1. P. neglecta. Morphology A-D. (A) General aspect of fruit and seed morphology. B) Detail of the seed. (C) Longitudinal section showing the position of the embryo. (D) Appearance of the embryo. Anatomy E-N. (E) General view of the cross section of the fruit and seed. (F) Detail of the pericarp and seed coat. (G) Detail of crystals in the mesocarp and endocarp, under polarized light. $(\mathrm{H})$ General view of the cross section of the seed. (I) Detail of the head and tegmen. (J) Detail of the crisscrossed sclereids. (K) Detail of the fruit and seed, showing cells that contain lipid droplets. (L) Detail of the cross section of the embryo. (M) General view of the longitudinal cut of the fruit and seed. (N) Detail of the longitudinal cut of the fruit and seed. co=cotyledons, cr=crystals, em =embryo, en=endocarp, ep=epicarp, es=sclereids, $\mathrm{gl}=\mathrm{lipid}$ drops, $\mathrm{hv}=$ =vascular bundles, me=mesocarp, pe=pericarp, rad=radicle, se=seed, su=suture, te=head, $\operatorname{tg}=$ tegmen.

$4.3 \pm 0.9 \mathrm{~mm}$ de ancho (Tabla 1 ), con 4 a 6 proyecciones laterales algo irregulares en cuanto a la forma y tamaño, endurecidas y punzantes, que forman costillas evidentes. Además, en la región basal se observa una estructura aristada también endurecida y punzante (Figuras 2A, 2E, 3A y 3E). Las semillas de las tres especies son de color castaño claro, lisas, con $\sim 4 \mathrm{~mm}$ de longitud por $2 \mathrm{~mm}$ de ancho (Tabla 1), forma ovada-turbinada, 


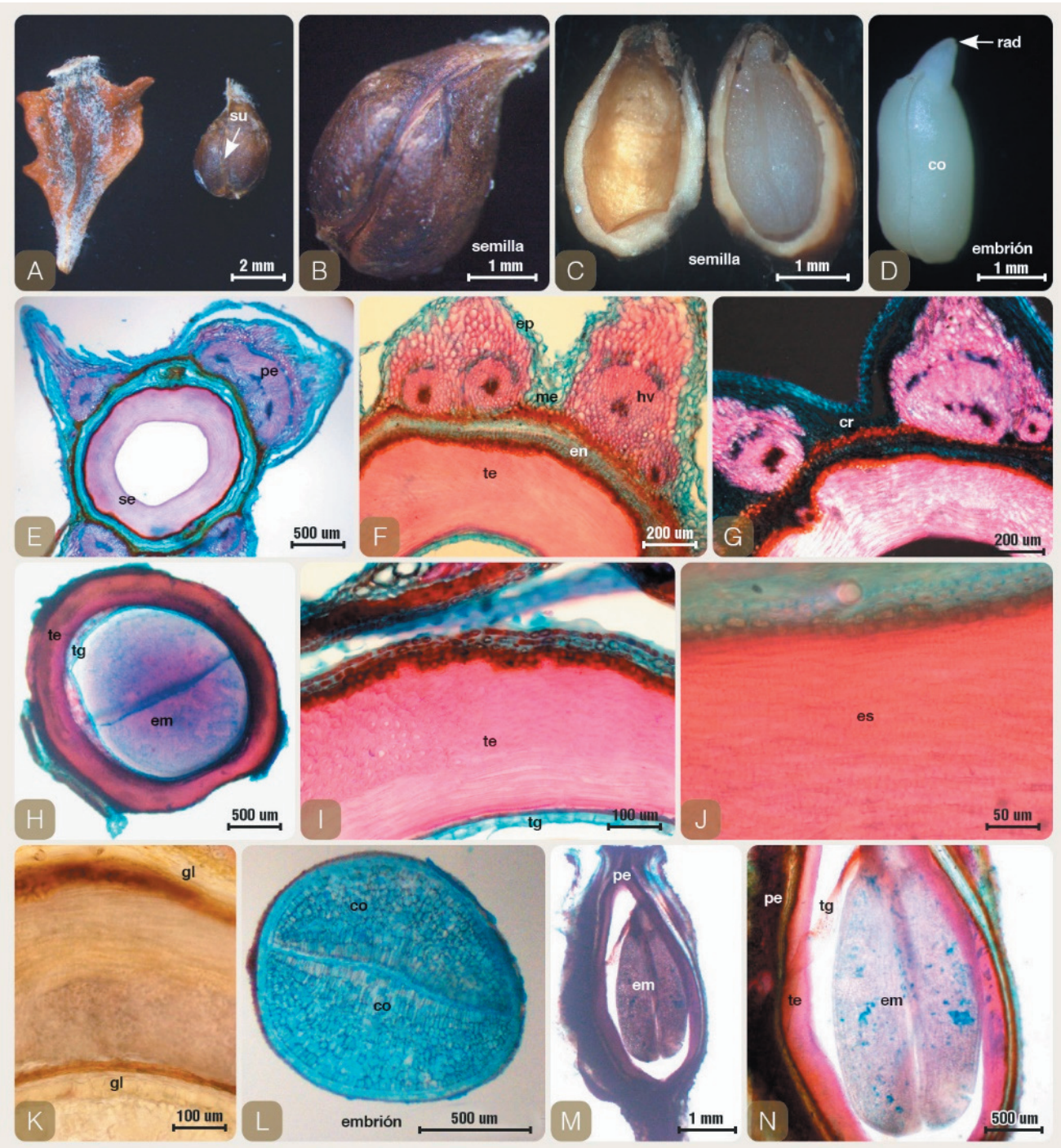

Figura 2. P. incarum. Morfología A-D. (A) Aspecto general de la morfología del fruto y semilla. (B) Detalle de la semilla. (C) Corte longitudinal de la semilla mostrando la posición del embrión. (D) Aspecto del embrión. Anatomía E-N. (E) Vista general del corte transversal del fruto y semilla. (F) Detalle del pericarpo y testa de la semilla. (G) Detalle de cristales en el mesocarpo y endocarpo, bajo luz polarizada. (H) Vista general del corte transversal de la semilla. (I) Detalle de la testa y tegmen. (J). Detalle de las esclereidas entrecruzadas. (K) Detalle del fruto y semilla, mostrando células que contienen gotas lipídicas (L) Detalle del corte transversal del embrión. (M) Vista general del corte longitudinal del fruto y semilla. (N) Detalle del corte longitudinal del fruto y semilla. co=cotiledones, cr=cristales, em=embrión, en=endocarpo, ep=epicarpo, es=esclereidas, gl=gotas lipídicas, hv=haces vasculares, me=mesocarpo, $\mathrm{rad}=$ radícula, se=semilla, su=sutura, te=testa, tg=tegmen .

Figure 2. P. incarum. Morphology A-D. (A) General aspect of fruit and seed morphology. B) Detail of the seed. (C) Longitudinal section showing the position of the embryo. (D) Appearance of the embryo. Anatomy E-N. (E) General view of the cross section of the fruit and seed. (F) Detail of the pericarp and seed coat. (G) Detail of crystals in the mesocarp and endocarp, under polarized light. (H) General view of the cross section of the seed. (I) Detail of the head and tegmen. (J) Detail of the crisscrossed sclereids. (K) Detail of the fruit and seed, showing cells that contain lipid droplets. (L) Detail of the cross section of the embryo. (M) General view of the longitudinal cut of the fruit and seed. (N) Detail of the longitudinal cut of the fruit and seed. $\mathrm{co}=$ cotyledons, $\mathrm{cr}=$ crystals, em $=\mathrm{embryo}$, en=endocarp, ep=epicarp, es=sclereids, gl=lipid drops, hv=vascular bundles, me=mesocarp, pe=pericarp, rad=radicle, se=seed, su=suture, te=head, $\mathrm{tg}=$ tegmen.

más anchas y redondeadas en la región basal y puntiagudas en el extremo apical; además, muestran dos suturas longitudinales dorsoventrales que corresponden a la región de unión con la pared del fruto. Internamente se observan dos tegumentos y un embrión recto, con dos cotiledones planos (Figuras 1B-D, 1M-N, 2B-D, 2M-N, 3B-D y 3M-N). Al relacionar la forma de la semilla con $\mathrm{su}$ estructura interna, se nota que la región 

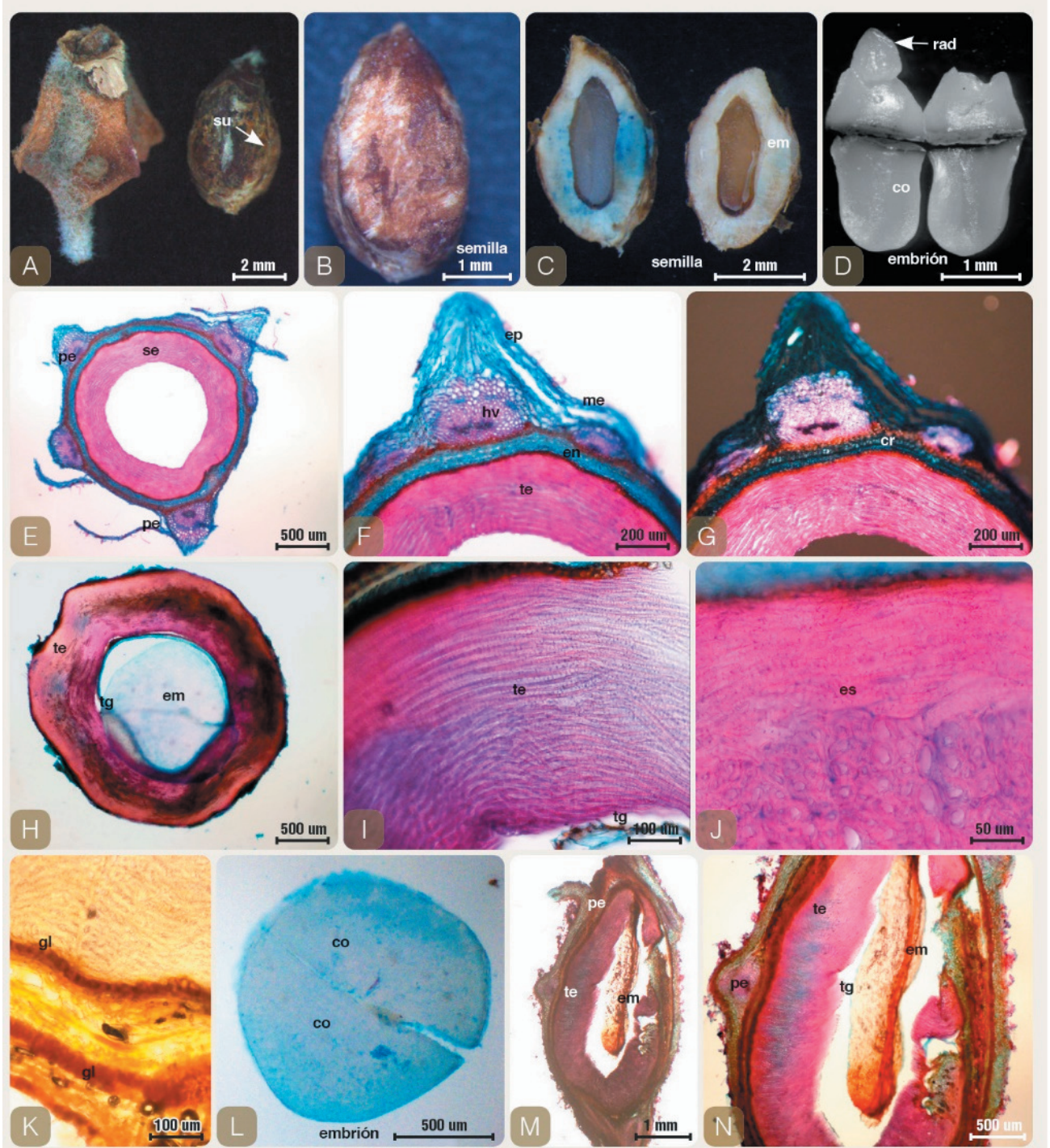

Figura 3. P. pacensis. Morfología A-D. (A) Aspecto general de la morfología del fruto y semilla. (B) Detalle de la semilla. (C) Corte longitudinal mostrando la posición del embrión. (D) Aspecto del embrión. Anatomía E-N. (E) Vista general del corte transversal del fruto y semilla. (F) Detalle del pericarpo y testa de la semilla. (G) Detalle de cristales en el mesocarpo y endocarpo, bajo luz polarizada. (H) Vista general del corte transversal de la semilla. (I) Detalle de la testa y tegmen. (J). Detalle de las esclereidas entrecruzadas. (K) Detalle del fruto y semilla, mostrando células que contienen gotas lipídicas. (L) Detalle del corte transversal del embrión. (M) Vista general del corte longitudinal del fruto y semilla. (N) Detalle del corte longitudinal del fruto y semilla. co=cotiledones, $\mathrm{cr}=$ cristales, em=embrión, en=endocarpo, ep=epicarpo, es=esclereidas, $\mathrm{gl}=$ gotas lipídicas, $\mathrm{hv}=$ haces vasculares, $\mathrm{me}=$ mesocarpo, $\mathrm{pe}=$ pericarpo, rad=radícula, se=semilla, su=sutura, te=testa, tg=tegmen .

Figure 3. P. pacensis. Morphology A-D. (A) General aspect of fruit and seed morphology. B) Detail of the seed. (C) Longitudinal section showing the position of the embryo. (D) Appearance of the embryo. Anatomy E-N. (E) General view of the cross section of the fruit and seed. (F) Detail of the pericarp and seed coat. (G) Detail of crystals in the mesocarp and endocarp, under polarized light. $(\mathrm{H})$ General view of the cross section of the seed. (I) Detail of the head and tegmen. (J) Detail of the crisscrossed sclereids. (K) Detail of the fruit and seed, showing cells that contain lipid droplets. (L) Detail of the cross section of the embryo. (M) General view of the longitudinal cut of the fruit and seed. (N) Detail of the longitudinal cut of the fruit and seed. $c 0=$ cotyledons, $c r=c r y s t a l s, ~ e m=e m b r y o, ~ e n=e n d o c a r p$, ep=epicarp, es=sclereids, gl=lipid drops, hv=vascular bundles, me=mesocarp, pe=pericarp, rad=radicle, se=seed, su=suture, te=head, tg=tegmen.

ancha y redondeada corresponde al ápice de los cotiledones y el extremo puntiagudo a la radícula del embrión.
Anatomía. El fruto de las tres especies está conformado por un pericarpo protector adaptado a la dispersión de este órgano. 
Tabla 1. Dimensiones de los frutos y semillas de las tres especies de Polylepis.

Table 1. Dimensions of the fruits and seeds of the three Polylepis species.

\begin{tabular}{ccccc}
\hline & \multicolumn{2}{c}{ Fruto } & \multicolumn{2}{c}{ Semilla } \\
Especie & $\begin{array}{c}\text { Largo } \\
(\mathrm{mm})\end{array}$ & $\begin{array}{c}\text { Ancho } \\
(\mathrm{mm})\end{array}$ & $\begin{array}{c}\text { Largo } \\
(\mathrm{mm})\end{array}$ & $\begin{array}{c}\text { Ancho } \\
(\mathrm{mm})\end{array}$ \\
\hline P. neglecta & $5.47-8.34$ & $3.8-6.44$ & $3.02-4.27$ & $1.34-1.47$ \\
P. incarum & $4.62-8.26$ & $3.61-6.4$ & $3.47-4.41$ & $1.77-2.63$ \\
P.pacensis & $5.51-8.82$ & $2.83-4.69$ & $3.29-5.6$ & $2.16-3.13$ \\
\hline
\end{tabular}

En él se distinguen tres capas: epi, meso y endocarpo. El epicarpo es delgado, revestido por una capa de células epidérmicas con una cutícula fina y una hipodermis con células de paredes celulósicas. El mesocarpo exhibe las siguientes características: varias capas de células parenquimáticas de paredes celulósicas engrosadas, numerosos haces vasculares de xilema y floema, presentes por lo general en las proyecciones laterales, un cordón de cristales hexagonales y una capa parenquimática rica en gotas lipídicas. El endocarpo es delgado, parenquimatoso, con un cordón de células conteniendo gotas lipídicas y otro cordón de cristales hexagonales (Figuras 1E-G, 2E-G y 3E-G). Internamente, la semilla está constituida por dos tegumentos (la testa y el tegmen) y un embrión (Figuras $1 \mathrm{H}, 2 \mathrm{H}$ y $3 \mathrm{H})$. La testa, o tegumento externo, es bastante engrosada y está constituida por esclereidas alargadas, con paredes lignificadas engrosadas y puntuaciones conspicuas; además, presenta regiones bien diferenciadas de esclereidas apiladas o sobrepuestas en una sola dirección y otras de esclereidas entrecruzadas en dirección opuesta a la anterior; éstas pueden cambiar de dirección a lo largo de toda la testa. El tegmen, tegumento interno de la semilla, es delgado, con parénquima rico en gotas lipídicas y una capa epidérmica cubierta por una cutícula delgada (Figuras 1I-K, 1N, 2I-K, 2N, 3I-K y 3N). El embrión es dicotiledonar. En corte transversal, los cotiledones presentan forma plano convexa, externamente rodeados por una epidermis con cutícula delgada e internamente constituidos por un parénquima de reserva. Sólo en posición subepidérmica de la superficie plana se distinguen dos capas de células parenquimáticas en empalizada (Figuras 1L, 2L y 3L).

\section{Análisis de calidad de semillas}

Calidad física. En $100 \mathrm{~g}$ de semilla de $P$. neglecta, el $57 \%$ correspondió a semilla pura $\mathrm{y}$, en el caso de $P$. incarum, el $50 \%$. En lo que respecta a $P$. pacensis, no se generó dicha información puesto que sólo se llegó a un máximo de $30 \mathrm{~g}$ de los $100 \mathrm{~g}$ requeridos para este análisis. Con respecto al contenido de humedad de las semillas, para $P$. neglecta se registró un $6 \%$, un $8 \%$ para $P$. pacensis y un $10 \%$ para $P$. incarum. Los valores medios obtenidos para el parámetro de calidad física del peso de 1000 semillas de cada especie mostraron que en $P$. neglecta pesan $4.78 \mathrm{~g}$, en $P$. incarum $9.65 \mathrm{~g}$ y en $P$. pacensis $5.31 \mathrm{~g}$.

Calidad fisiológica. En función de los resultados obtenidos en la prueba de tetrazolio se pudieron diferenciar distintos patrones de coloración en los tejidos de las semillas (Tabla 2). En P. neglecta se observó $40 \%$ de semillas con coloración de tejido rojo intenso (TV1), $22 \%$ con tejido muerto (TM2) y $17 \%$ de semillas vacías (sin embrión). En $P$. incarum se verificó $48 \%$ de semillas con coloración marrón (TM2) y $20 \%$ con coloración de tejido descolorido/ blancuzco o hialino (TM1), condición que indica la muerte del tejido en ambos casos. En $P$. pacensis se registró $58 \%$ de semillas con tejido muerto (TM2) y 21\% de semillas vacías, sin la formación de tejidos embrionarios (SSTE). El resto de los porcentajes presentados en menor proporción en las tres especies corresponden a otras categorías que se muestran en la Tabla 2. A su vez, las diferentes categorías de coloración establecidas para determinar la viabilidad de las semillas se pueden observar en la Figura 4. De manera general, los resultados arrojados a través de esta prueba muestran un porcentaje alto de semillas no viables en $P$. incarum y $P$. pacensis $(76$ y $85 \%$, respectivamente), mientras que en $P$. neglecta se registró un menor porcentaje de semillas no viables (42\%). Los principales resultados del ensayo de germinación mostraron una tasa de germinación de $42 \%$ para $P$. neglecta y $10 \%$ para $P$. incarum y $P$. pacensis, después de 30 días de evaluación, definido éste como el período de observación en el que ocurrió la máxima germinación acumulada.

\section{Germinación de semillas en invernadero}

Los resultados del ensayo preliminar, a los 45 días de evaluación (tiempo máximo de germinación), mostraron sólo diferencias estadísticas significativas con respecto a los factores especies (A) y sustratos (C), no así para el factor remojo (B), ni para ninguna de las interacciones entre factores. De acuerdo con ello se analizaron ambos factores por separado a través de la prueba de rango 
Tabla 2. Porcentaje de semillas de acuerdo con las categorías de tinción con tetrazolio (TZ).

Table 2. Percentage of seeds according to the categories of tetrazolium staining (TZ).

\begin{tabular}{lccccccccc}
\hline Especie & $\begin{array}{c}\text { Categoría 1 } \\
\text { Tejido vivo }\end{array}$ & $\begin{array}{c}\text { Categoría 2 } \\
\text { Tejido deteriorado }\end{array}$ & $\begin{array}{c}\text { Categoría 3 } \\
\text { Tejido muerto }\end{array}$ & $\begin{array}{c}\text { Categoría } 4 \\
\text { Semilla vacía }\end{array}$ & $\begin{array}{c}\text { Total de semillas } \\
\text { evaluadas }\end{array}$ \\
\hline P. neglecta & 40 & 16 & 2 & 0 & 0 & 3 & 22 & 17 & 100 \\
P. incarum & 6 & 10 & 8 & 0 & 0 & 20 & 48 & 8 & 100 \\
$P$. pacensis & 9 & 2 & 4 & 0 & 1 & 5 & 58 & 21 & 100 \\
\hline
\end{tabular}

TV1: coloración de tejido rojo intenso. TV2: coloración de tejido rosado brillante o intensa. TV3: coloración de tejido rosado claro). TD1: coloración de tejido rojo granate. TD2: coloración de tejido rosado lechoso. TM1: coloración de tejido descolorido/blancuzco o hialino. TM2: tejido necrosado (coloración marrón). SSTE: semilla vacía sin tejidos embrionarios.

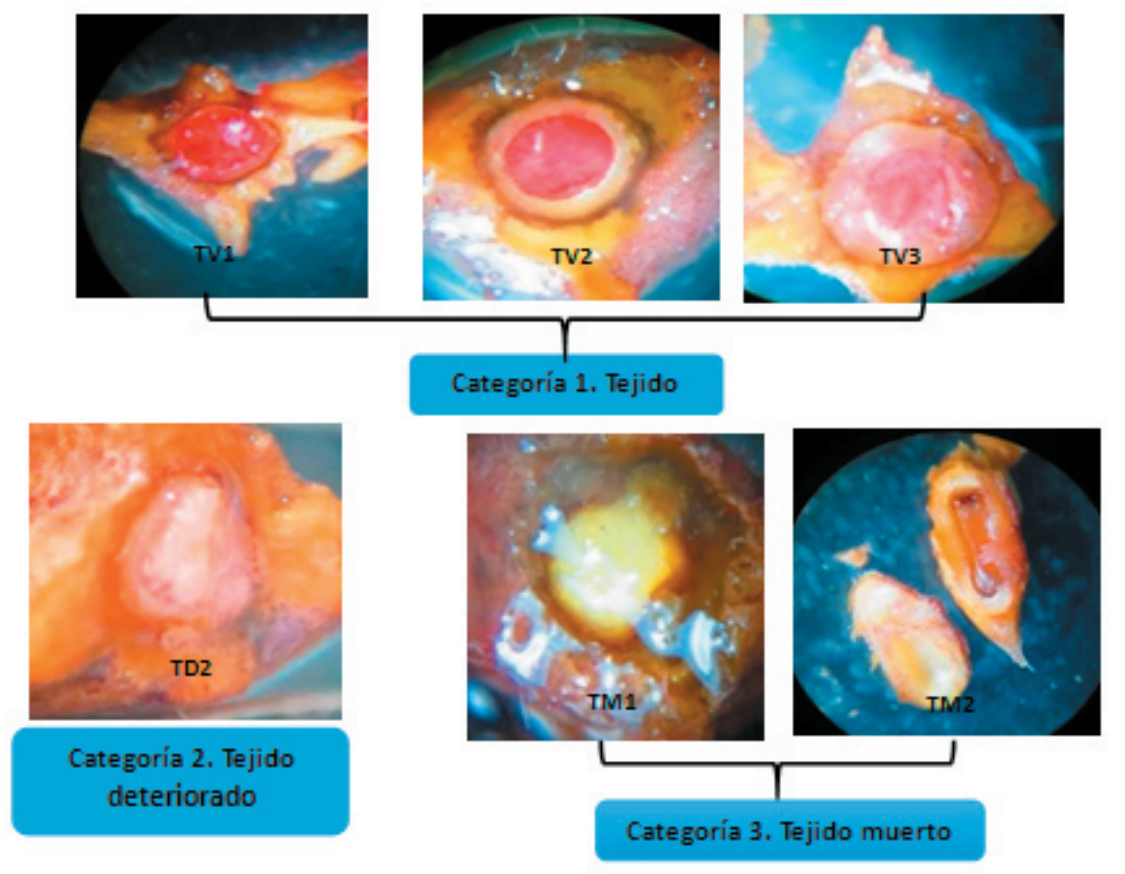

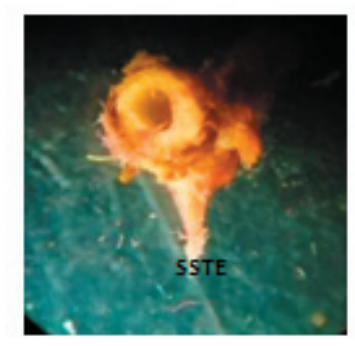

Categoria 4. Semilla vacia
Figura 4. Semillas coloreadas con tetrazolio, distribuidas entre tejidos vivos, deteriorados, muertos y semillas vacías.

Figure 4. Colored seeds with tetrazolium, distributed among living, deteriorated, dead tissues and empty seeds. múltiple de Duncan $(\alpha=0.05)$, que identificó como el porcentaje de germinación más alto al registrado para $P$. neglecta $(15 \%)$, siendo que este es estadísticamente distinto a los obtenidos para P. incarum y P. pacensis (Figura 5a). Con respecto a las diferencias identificadas para el factor sustrato, a través de la prueba de Duncan $(\alpha=0.05)$ se verificó que el sustrato S1 (arena+turba 1:1) presentó la mayor tasa de germinación $(19 \%)$ con relación a los otros sustratos (Figura 5b). En este sentido, al tratarse de factores de evaluación se puede afirmar que el sustrato S1 es el que presenta mejor tasa de germinación para todas las especies en 

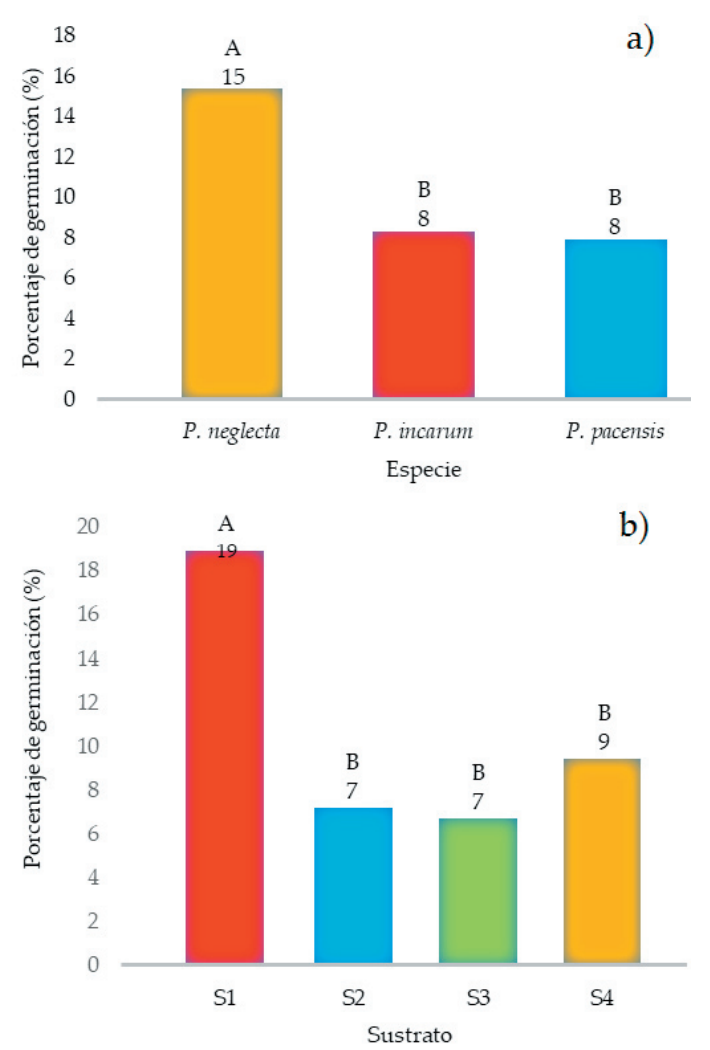

Figura 5. Resultados de germinación de semillas de especies de Polylepis en condiciones de invernadero (ensayo preliminar). a) Porcentaje de germinación promedio por tipo de sustrato. b) Porcentaje de germinación promedio registrado por especie. * De acuerdo con Duncan $(\alpha=0.05)$. Letras distintas son estadísticamente diferentes.

Figure 5. Seed germination results of Polylepis species under greenhouse conditions (preliminary test). a) Percentage of average germination per type of substrate. b) Percentage of average germination registered by species. *According to Duncan $(\alpha=0.05)$. Different letters are statistically different.

estudio y la especie con mejor comportamiento germinativo independientemente del sustrato o el remojo es $P$. neglecta. Los resultados del ensayo final revelaron diferencias estadísticas significativas con respecto a las especies en estudio (A) y los tratamientos (B), y no así para la interacción $(\mathrm{AB})$. De esta manera, la prueba de Duncan $(\alpha=0.05)$ identificó nuevamente a $P$. neglecta como la especie que alcanzó el mayor porcentaje de germinación $(10 \%)$, seguida de $P$. pacensis $(8 \%)$ y finalmente $P$. incarum $(2 \%)$ (Figura 6a). Asimismo, esta prueba mostró que los tratamientos con mayor porcentaje de germinación corresponden al sustrato S1 (arena+turba 1:1), independientemente del efecto del tratamiento pre-germinativo de remojo (Figura 6b). En resumen, se puede confirmar que el sustrato $\mathrm{S} 1$, independientemente del remojo, fue el que
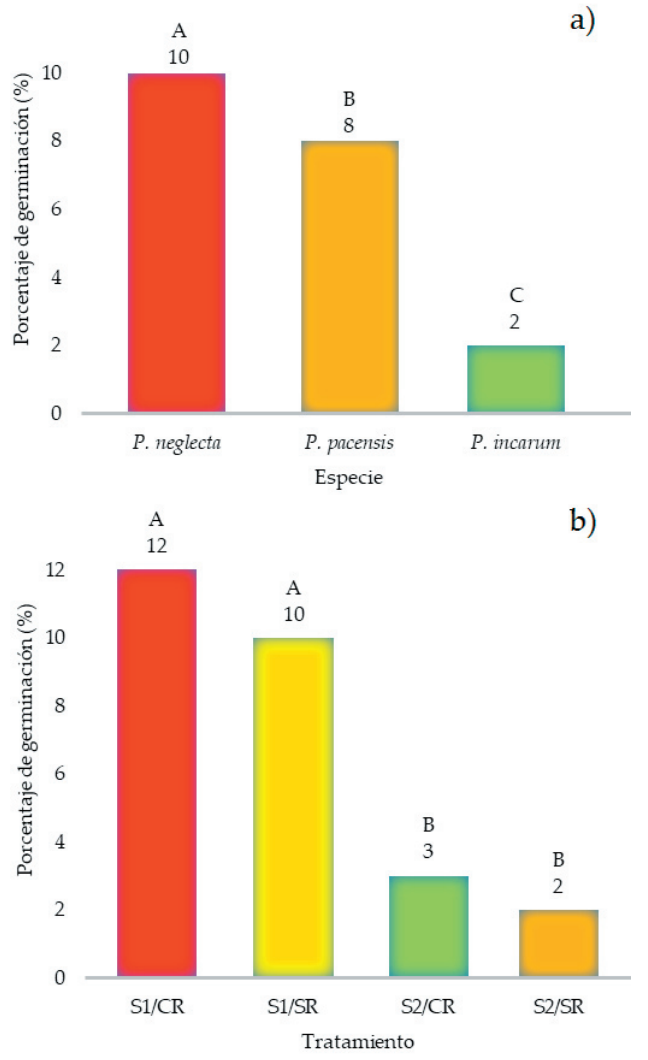

Figura 6. Resultados de germinación de semillas de especies de Polylepis en condiciones de invernadero (ensayo final). a) Porcentaje de germinación registrado en función al tipo de sustrato y tratamiento pre-germinativo. b) Porcentaje de germinación registrado por especie.* De acuerdo con Duncan $(\alpha=0.05)$. Letras distintas son estadísticamente diferente

Figure 6. Seed germination results of Polylepis species under greenhouse conditions (final test). a) Percentage of germination registered according to the type of substrate and pre-germinative treatment. b) Percentage of germination registered by species.* According to Duncan $(\alpha=0.05)$. Different letters are statistically different.

presentó la mejor tasa de germinación para las tres especies. El mejor comportamiento germinativo, independientemente del sustrato o el remojo, le correspondió a $P$. neglecta.

\section{Discusión}

\section{Caracterización morfoanatómica de frutos y semillas}

Se encontró que la morfología de los frutos de las especies estudiadas concuerda con las descripciones hechas para otras especies del género Polylepis (Simpson 1979). Con respecto a la anatomía de las semillas, la testa posee esclereidas con diferentes configuraciones, las que, según Cutter (1987), contribuyen a la dureza de la cubierta seminal y provocan 
impermeabilidad de las semillas al agua y al intercambio gaseoso. Este factor podría afectar la germinación. Probablemente, esta sería una de las causas del bajo porcentaje y tiempo de germinación de las semillas registrados para Polylepis tarapacana (Compañía Minera Doña Inés de Collahuasi SCM 2011), aunque estos autores afirman que la testa no es dura y no limita físicamente la germinación. En las tres especies estudiadas se observaron semillas no viables, con embriones poco desarrollados o no formados, consideradas también como una de las causas para la obtención de bajos porcentajes de germinación (Compañía Minera Doña Inés de Collahuasi SCM 2011; Pretell et al. 1985), que se originarían por la dicogamia y la polinización anemófila características del género Polylepis (Pretell et al. 1985). De acuerdo con Renison y Cingolani (1998) y Pretell et al. (1985), la presencia de semillas no viables ocurre con mayor frecuencia en lugares donde las poblaciones de Polylepis son reducidas o con individuos aislados, posiblemente por la falta de polen para asegurar la fecundación y, por ende, la producción de semillas viables; también podría ser una de las explicaciones para la alta proporción de semillas vacías registradas en el presente estudio, tomando en cuenta además las características de las poblaciones donde realizaron las colectas. Por consiguiente, para fines de reforestación es conveniente recolectar las semillas de bosques de considerable extensión, que tienen las condiciones necesarias para la formación de frutos y semillas viables (Renison and Cingolani 1998; Inga 1995).

\section{Análisis de calidad de semillas}

Con respecto a los parámetros de calidad física, en el caso de pureza física, las semillas presentaron alto grado de impurezas $(47 \%$ en promedio), lo que dificulta la obtención de semilla pura para una futura siembra. Su importancia radica en que un lote de semillas con mucho material inerte es de menor calidad e implica la necesidad de utilizar mayor cantidad de este material para que el proceso sea más efectivo (Ciencia y Tecnología de Semillas 2002). Por otra parte, el contenido de humedad es uno de los factores más importantes que afecta al mantenimiento de la calidad de las semillas. Así, las semillas secas y sanas pueden ser mantenidas bajo almacenamiento apropiado por muchos más años, mientras que semillas húmedas se pueden deteriorar en pocos días. El tiempo de almacenamiento de semillas disminuye a medida que el contenido de humedad aumenta, ya que tiene un efecto dominante en el predominio y en la actividad de insectos y hongos durante el almacenamiento (Bautista 2012). El contenido de humedad afecta la actividad metabólica de las semillas en la germinación y el deterioro de éstas; por tanto, el conocimiento de este atributo permite elegir el procedimiento más adecuado para la cosecha o colecta de semillas, su acondicionamiento, la preservación de la calidad física, fisiológica y sanitaria de la semilla (Ciencia y Tecnología de Semillas 2002). En el caso de las especies estudiadas, no se tienen parámetros de humedad recomendados como óptimos para su almacenamiento. Sin embargo, de acuerdo con el ISTA (2003) se considera como norma que la humedad de las semillas para ser comercializadas no debe exceder el 13\% (Ciencia y Tecnología de Semillas 2002). El contenido de humedad de todas las especies en estudio fue bajo, por lo cual podrían considerarse semillas ortodoxas, que son aquellas cuyo contenido de humedad puede ser reducido a valores entre $5 \%$ y $10 \%$ y almacenarlas a temperaturas bajo cero sin dañarlas; esto permite su conservación por períodos largos sin que se pierda su poder germinativo (Serrada 2000). De acuerdo con el documento publicado por la Compañía Minera Doña Inés de Collahuasi SCM (2011), semillas de $P$. tarapacana almacenadas por un año en una bodega seca a temperatura ambiente no perdieron su viabilidad, por lo que el porcentaje de germinación no se vio afectado. El peso de 1000 semillas permite establecer la cantidad necesaria de semillas para lograr un número de plantas determinado. Si se conoce el valor de este parámetro, es fácil fijar la cantidad de semillas a ser utilizadas por área de reforestación (Bautista 2012). De acuerdo con lo observado en el presente estudio, se puede inferir que para contar con 1000 semillas de $P$. neglecta y $P$. pacensis se requiere entre 4 y $6 \mathrm{~g}$, mientras que en $P$. incarum se requeriría alrededor de $9 \mathrm{~g}$. Con relación a la calidad fisiológica, a través de la prueba de viabilidad de tetrazolio en semillas de Polylepis se verificaron porcentajes altos de semillas no viables y de semillas vacías, lo que estaría relacionado con el bajo porcentaje de germinación que se registra en diferentes especies del género Polylepis. Al respecto, Pretell et al. (1985), mencionan que en la recolección de semillas correspondientes a $P$. incana, muchos árboles llegaron a tener casi todas sus semillas vacías. Otro resultado muy interesante es el reportado por Seltmann et al. 
(2007) para P. australis (Córdoba-Argentina), en el que analizaron el efecto de la masa de semillas, la región geográfica, los fragmentos de bosque y los árboles individuales sobre la germinación de las semillas, y reportaron que las semillas que no germinaron casi siempre estaban vacías. Asimismo, estos autores hacen referencia a Hensen (datos no publicados), quien encontró un alto porcentaje de semillas vacías y no viables en varias especies de Polylepis bolivianas $(P$. hieronymi, $80 \%$; P. tomentella, $84 \%$; P. besseri, de 90 a $100 \%$; P. racemosa, 100\%; P. tarapacana, $100 \%$ ). La presencia de altos porcentajes de semillas vacías parece ser una característica en las especies de Polylepis, lo que representa un problema a la hora de realizar planes de forestación o reforestación. Al respecto, Seltmann et al. (2007) determinaron la existencia de una correlación positiva entre la masa y la germinación de semillas de $P$. australis, es decir que el peso de la semilla podría ser una manera rápida para poder evaluar la viabilidad de estas y, por lo tanto, sería una alternativa práctica para la selección de las semillas y asegurar tasas más altas de geminación.

Con relación al ensayo de germinación realizado, los reportes disponibles registraron bajas tasas de germinación en las especies estudiadas, lo cual se verificó en los datos obtenidos para este estudio. Por ejemplo, experiencias de germinación de $P$. incana en cajas Petri de muestras tomadas a diferentes altitudes mostraron porcentajes de germinación entre 8 y $34 \%$ en un período de 15 a 49 días (recolección de semillas a $3100 \mathrm{~m}$ s. n. m.). Asimismo, muestras recolectadas a una altitud de $3600 \mathrm{~m} \mathrm{s.} \mathrm{n.} \mathrm{m.,} \mathrm{con} \mathrm{tratamiento}$ pregerminativo consistente en remojo en agua por 42 horas previo a la siembra, arrojaron porcentajes de germinación entre 12 y $44 \%$ (CESA 1991).

\section{Germinación de semillas en invernadero}

Con respecto a la germinación para la producción de plantines en otras especies de Polylepis en condiciones de invernadero, diferentes trabajos reportan experiencias en las que se mencionan resultados similares a los presentados en esta publicación. Con relación al tipo de sustrato, Fjledså y Kessler (2004) recomiendan una mezcla de arena+turba en proporción 1:1, que en los ensayos realizados en el presente estudio resultó ser el sustrato en el que germinaron la mayor cantidad de semillas de las tres especies analizadas. $\mathrm{Si}$ bien algunas investigaciones recomiendan someter las semillas a un remojo en agua por $24 \mathrm{~h}$ como tratamiento pregerminativo (Reynel and León 1990; BASFOR 2001), los resultados en este trabajo no evidenciaron un efecto marcado sobre la germinación de las especies en estudio, por lo cual su uso resultó indistinto en función de los datos obtenidos. Respecto al tiempo de germinación, las primeras plántulas emergieron entre los 20 y 25 días en $(P$. neglecta, $P$. incarum y $P$. pacensis, registrándose este evento hasta los 45 días en los distintos ensayos realizados). Estudios efectuados en P. tarapacana demostraron que la aparición de plántulas se concentró entre los 30 y 40 días a partir de la siembra (Compañía Minera Doña Inés de Collahuasi SCM 2011), mientras que en el caso de $P$. australis, las primeras plántulas se observaron a los 20 días después de la siembra y su número aumentó hasta los 60 días (Renison and Cingolani 1998).

Los resultados de esta investigación demostraron porcentajes de germinación variables. P. neglecta registró un $10 \%$, P. pacensis un $8 \%$ y $P$. incarum un $2 \%$. Existen reportes acerca del bajo poder germinativo en especies de Polylepis. Por ejemplo, para P. incana (Perú) se tiene información de que el porcentaje de germinación varía entre 2 y 15\%, según Fjledså y Kessler (1996). En P. tomentella se tiene un $3.1 \%$ (Cruz 1999), y en $P$. australis se tiene una variación de 10 y 50\% de porcentaje de germinación bajo condiciones experimentales (Renison and Cingolani 1998). En el estudio realizado por la Compañía Minera Doña Inés de Collahuasi SCM (2011) se menciona que el porcentaje de germinación en propagación masiva en $P$. tarapacana fluctuó notablemente según la procedencia de las semillas, en un rango de 2 a $10 \%$, con un promedio cercano al $4 \%$. En P. besseri, la conclusión de la etapa germinativa se dio entre los 50 a 65 días, con una tasa de germinación de 3 a 10\% en parcelas experimentales (Hensen 1994), mientras que, en $P$. racemosa, el éxito germinativo fue de 2 a $15 \%$, en un período de 60 a 70 días (Reynel and León 1990). Por consiguiente, la tasa de éxito de propagación dependerá principalmente de la cantidad de semillas viables existentes y de las condiciones ambientales adecuadas (suelo, humedad y temperatura) que les sean proporcionadas para la germinación (Prettel et al. 1985). Por otra parte, es importante tomar en cuenta la distribución de los árboles semilleros de donde se obtuvieron las muestras, ya sea en la ciudad como en 
el campo, aspecto que puede dar respuesta a la baja tasa germinativa presentada en las especies en estudio. Según Seltmann et al. (2007), el cruce entre plantas vecinas puede conducir a una depresión biparental de endogamia, es decir, una pérdida de la eficacia biológica (vigor, viabilidad, fecundidad) a causa de la reducción de la variabilidad genética debido a la homocigosidad, lo que reduce las posibilidades de supervivencia de la especie. Por este motivo, se debería tener en cuenta que la recolección de semillas se realice en lugares donde se pueda evidenciar un flujo amplio de dispersión que, de cierta manera, garantice mayor variabilidad genética dentro de esa población.

\section{CONSIDERACIONES FINALES}

En base a todo lo anteriormente expuesto, el presente estudio logró generar información básica de referencia, enfocada principalmente a la descripción interna y externa de los frutos y semillas, aportando de esta manera con el conocimiento de la biología de $P$. neglecta, $P$. incarum y $P$. pacensis. Por otra parte, el trabajo aporta datos de localización, descripción y selección de ejemplares semilleros de Polylepis en áreas próximas o pertenecientes al Municipio de La Paz, de determinación de parámetros relacionados a la calidad física y fisiológica de semillas, y también del desarrollo de procedimientos de base para su cultivo inicial en condiciones controladas (invernadero). De esta manera, se pretende contribuir al conocimiento biológico de las especies examinadas, llenando algunos vacíos de información para comprender su estado actual y planificar el desarrollo de estrategias adecuadas de conservación in situ y ex situ de las especies en estudio mediante programas de restauración o reforestación con plantines obtenidos por semilla.

Agradecimientos. Agradecemos al Departamento de Investigación Postgrado e Interacción Social - DIPGIS, por el financiamiento otorgado para la realización de la presente investigación a través de los fondos concursables IDH 2013-2014 UMSA. A las investigadoras J.C. Bermejo, I. Gómez, A. Palabral y A. Domic, por la colaboración estrecha con esta iniciativa, lo cual permitió desarrollar un trabajo sinérgico de cooperación interdisciplinaria. A la Lic. R.I. Meneses, por permitirnos el uso de ambientes para el procesamiento y almacenamiento en el Herbario Nacional de Bolivia de las colecciones botánicas del proyecto.

\section{ReFERENCIAS}

Arrázola, S., I. Coronado, L. Torrico, R. I. Meneses, G. Navarro, and W. Ferreira. 2012. Polylepis incarum (Bitter) M. Kessler \& Scmidt-Leb. Pp. 44-45 en Libro Rojo de la Flora Amenazada de Bolivia, Volumen I. Zona Andina, Ministerio de Medio Ambiente y Agua, La Paz, Bolivia.

Arrázola, S., and I. Coronado. 2012. Polylepis pacensis M. Kessler and Schmidt-Leb. Pp. 338-339, Polylepis neglecta M. Kessler. Pp. 535-536 en Libro Rojo de la Flora Amenazada de Bolivia, Volumen I. Zona Andina, Ministerio de Medio Ambiente y Agua, La Paz, Bolivia.

Bautista, A. 2012. Manual de ensayos de semillas forestales. Secretaría de Medio Ambiente. México.

BASFOR. 2001. Banco de Semillas Forestales. Catálogo de semillas forestales. Cochabamba, Bolivia.

CESA. 1991. Experiencias sobre reforestación en la sierra ecuatoriana, con especies nativas. Ecuador. Pp. 30. URL: https: //goo.gl/tYyL7U (consultada en junio 2018).

Ciencia y Tecnología de Semillas. 2002. Módulo Análisis de Semillas. Curso de Especialización en Ciencia y Tecnología de Semillas. Ministerio de Educación. Universidad Federal de Pelotas RS. Brasil.

Compañía Minera Doña Inés de Collahuasi SCM, 2011. Queñoa árbol de las alturas. Santiago de Chile, Chile.

Cruz, A. S. 1999. Efecto de sustratos orgánicos en la reproducción vegetativa de la queñua (P. incana, H.B.K.) Rosoideae. Tesis de Grado. Facultad de Agronomía. Universidad Mayor de San Andrés, La Paz. Bolivia. Pp. 90-92.

Cutter, E. G. 1987. Anatomía Vegetal. Parte II : Órgãos experimentos e interpretação. Segunda Edición. Roca. Sao Paulo, Brasil.

Danida, and FAO. 1991. Guía para la manipulación de semillas Forestales. Centro de semillas Forestales. Roma, Italia.

Domic, A. I., A. N. Palabral, M. I. Gómez, R. Hurtado, N. Ortuño, and M. Liberman. 2017. Polylepis incarum (Rosaceae) una especie En Peligro Crítico en Bolivia: Propuesta de reclasificación en base al área de ocupación y estructura poblacional. Ecología en Bolivia 52:116-131.

Fjeldså, J., and M. Kessler. 2004. Conservación de la biodiversidad de los bosques de Polylepis de las tierras altas de Bolivia. Una contribución al manejo sustentable en los Andes. DIVA Technical Report 11. Editorial FAN, Santa Cruz de la Sierra, Bolivia.

Fjeldså, J., and M. Kessler. 1996. Conserving the Biological Diversity of Polylepis woodlands of the highland of Peru and Bolivia. A Contribution to Sustainable Natural Resource Management in the Andes. NORDECO, Copenhagen, Denmark. 
Gómez, M. I., A. N. Palabral, A. I. Domic, R. R. Hurtado, and M. C. Liberman. 2014. Los bosques de keñua en La Paz. Cartilla para conservar y conocer nuestros bosques. La Paz, Bolivia.

Hensen, I. 1994. Estudios ecológicos y fenológicos sobre Polylepis besseri Hieron. en la Cordillera Oriental Boliviana. Ecología en Bolivia 23:21-26.

Inga, M. 1995. Propagación vegetativa por esquejes de Polylepis incana, en la Provincia de Imbabura. Tesis de grado. Facultad de Ingeniería en Ciencias Agropecuarias y Ambientales. Escuela de Ingeniería Forestal y Recursos Naturales Renovables. Universidad Técnica del Norte, Ibarra. Ecuador. Pp. 76.

International Seed Testing Association (ISTA). 1993. International rules for seed testing. Rules. Seed. Science and Technology.

Johansen, D. A. 1940. Plant microtechique. New York. McGraw Hill Book.

Kessler, M. 1995. Present and potential distribution of Polylepis (Rosaceae) forests in Bolivia. Pp 281-294 en S. P. Churchill, H. Balslev, E. Foresro and J. L. Luteyn (eds.). Biodiversity and conservation of Neotropical montane forests, New York, EE.UU.

Kessler, M. 2002. The "Polylepis problem": where do we stand? Ecotropica 8:97-110.

Kessler, M. 2006. Bosques de Polylepis. Pp. 110-120 en M. Moraes, B. Øllgaard, L. P. Kvist, F. Borchsenius and H. Balslev (eds.). Botánica Económica de los Andes Centrales. Universidad Mayor de San Andrés, La Paz, Bolivia.

Kessler, M., and A. N. Schmidt-Lebuhn. 2006. Taxonomical and distributional notes on Polylepis (Rosaceae). Organisms Diversity and Evolution 6:67-69.

Kessler, M., and P. Driesch. 1993. Causas e historia de la destrucción de bosques altoandinos de Bolivia. Ecología en Bolivia 21:1-18.

Lojan, L. 1992. Árboles y arbustos nativos para el desarrollo forestal andino. Segunda Edición, Latacunga, Quito, Ecuador.

Luque, R., H. C. Sousa, and J. E. Kraus. 1996. Métodos de coloracao de Roese (1972) - modificado - e Kropop (1972) visando a substituzo do azul de astra por azul de alcito 8 GS ou 8 GX. Acta Bot Bras 10:199-212.

MMAYA. 2012. Plan nacional para la conservación y manejo sostenible de los bosques de Polylepis (Kewiña, Keñua y/o Lampaya) y su biodiversidad asociada (Programas y Lineamientos Generales). EDOBOL, La Paz, Bolivia.

Navarro, G. 2002. Vegetación y unidades biogeográficas. Pp. 1-500 en G. Navarro and M. Maldonado (eds.). Geografía Ecológica de Bolivia. Vegetación y Ambientes Acuáticos. Centro Ecología Simón I. Patiño. Departamento de Difusión, Cochabamba, Bolivia.

Prettell, J., D. Ocaña, R. Jon, and E. Barahona. 1985. Apuntes sobre algunas especies forestales nativas de la sierra peruana. Proyecto FAO Holanda. Infor. Lima, Perú.

Renison, D., and A. Cingolani. 1998. Experiencias en germinación y reproducción vegetativa aplicados a la reforestación con Polylepis australis (Rosaceae) en las Sierras Grandes de Córdoba, Argentina. Agriscientia 15:47-53.

Renison, D., I. Hensen, and A. M. Cingolani. 2004. Anthropogenic soil degradation affects seed viability in Polylepis australis mountain forests of central Argentina. For Ecol Man 196:327-333.

Reynel, C. R., and J. G. León. 1990. Árboles y arbustos andinos para agroforestería y conservación de suelos. Tomo II. Las Especies. Proyecto FAO Holanda-DGFF. Perú.

Roth, I. 1964. Microtecnia vegetal. Caracas. Universidad Central de Venezuela.

Seltmann, P., I. Leyer, D. Renison, and I. Hensen. 2007. Variation of seed mass and its effects on germination in Polylepis australis: Implications for seed collection. New Forests 33:171-181.

Serrada, R. 2000. Apuntes de repoblaciones forestales. FUCOVASA, Madrid, España.

Simpson, B. 1979. A revision of genus Polylepis (Rosaceae: Sanguisorbae). Smithsonian Contr. Bot 43:1-62.

Stevens, W. C. 1916. Plant anatomy. London, J. and A. Churchill. 